\title{
The successful treatment of shepherd's crook deformity in fibrous dysplasia by ilizarov technique
}

\begin{abstract}
The management of fibrous dysplasia is challenging especially when faced with a large lesion involving the proximal femur resulting in the classical shepherd crook deformity. We report on a case of a 16 year old boy who was treated successfully for his pathological femur fracture on a background of fibrous dysplasia with a shepherd's crook deformity by using the Ilizarov technique.
\end{abstract}

Keywords: Fibrous dysplasia, shepherd's crooks deformity, Ilizarov apparatus
Volume 8 Issue 3 - 2017

\author{
Pang GMH,' Bari MM,' Islam S \\ 'Malaysian subspecialty program in Orthopaedic Advanced \\ Musculoskeletal Trauma, Fellow at Bari-llizarov Orthopaedic \\ Centre, Bangladesh \\ ${ }^{2}$ Chief Consultant, Bari-llizarov Orthopaedic Centre,Visiting and \\ Honored Prof, Russian llizarov Scientific Centre, Russia \\ ${ }^{3}$ Bari-llizarov Orthopaedic Centre, Dhaka, Bangladesh
}

Correspondence: Gerry Maxmillan Houjen Pang Hospital Tuanku Jaafar, Jalan Rasah, 70300 Seremban, Negeri Sembilan, Malaysia, Email maxmillan@yahoo.com

Received: May 16, 2017 | Published: May 23, 2017

\section{Introduction}

Shepherd's crook deformity refers to a distinctive abnormal contour of the proximal femur in the setting of Fibrous Dysplasia. The decreasing neck shaft angle (coxa vara) and the rounded appearance as the bone deformed resembles that of a staff with a C-shaped end carried by shepherds. Fibrous dysplasia is a benign bone tumour in which abnormal tissue develops in place of normal bone. Bone lesions are characterized by woven ossified tissue and extensive marrow fibrosis which decrease the mechanical quality. As a consequence, fibrous dysplasia bone is fragile and patients have an increased risk of developing abnormalities, pain and pathological fractures. We report a case of a 16 year-old boy who has a shepherd's crook deformity of the right femur secondary to fibrous dysplasia, who sustained a chronic fatigue fracture of the proximal femur and successfully treated by the Ilizarov technique.

\section{Case presentation}

A 16 year-old boy presented to us with right hip pain in 2016 Clinical examination demonstrated shortening of the right lower limb with painful hip movements and inability to weight bear. There was also a well-healed surgical scar over the right hip. Plain radiograph of the hip revealed a subthrocanteric fracture on a background of fibrous dysplasia with a shepherd's crook deformity (Figure 1).

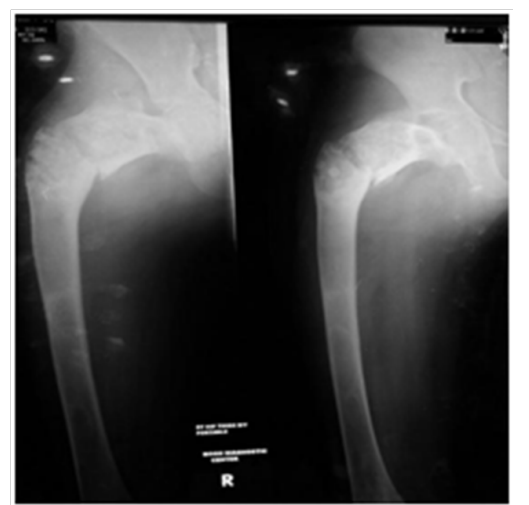

Figure I Plain radiograph of the hip revealed a subthrocanteric fracture on a background of fibrous dysplasia with a shepherd's crook deformity.
On further questioning, he was treated for a hip fracture 2 years back in another hospital, where a dynamic hip screw was inserted. He went through the standard post-operative rehabilitation and was back on his feet allowing some sport activities, although at a lower functional level. He has always experience persistent pain over the old injury and shortening of the leg. At 6 months prior to seeing us, he under gone another surgery for removal of the Dynamic Hip Screw due to worsening hip pain. After making a thorough assessment, the surgical plan was to fix the fracture by close reduction and external fixation by application of the Ilizarov apparatus (Figure 2).

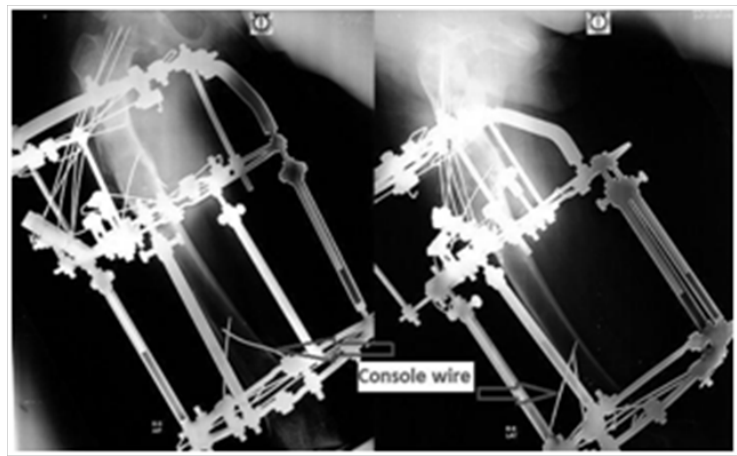

Figure 2 Pathological fracture of the femur stabilised with llizarov apparatus.

\section{Operative treatment}

The patient was placed supine on a traction table and femur was realigned by traction. Multiple Ilizarov wires were introduced through the femoral neck and the throcanteric region. These wires were held in position attached to a Russian femoral arch. The varus deformity was corrected at the fracture site by giving a valgus force on the Russian femoral arch and the fracture was stabilised by connecting it distally to two full rings at the shaft, tranfixed with intraosseos wires. Multipe console wires were introduced to the bone at strategic positions. The neck shaft angle was reduced to $130^{\circ}$. No osteotomy was done for this operation.

The patient was allowed partial weight bearing for the first 1 month and gradually progress to full weight bearing. At 3 months the patient was pain free on the Ilizarov frame, he demonstrated almost full range 
of movement of the hip and walk with less shortening. Radiograph at 6 months showed union at the fracture. At 10 months follow up, radiograph showed thickening of the cortex around the fibrous dysplasia lesion and increased bone density which replaced the cystic lesions (Figure 3 ). The frame was removed at 10 months post surgery.

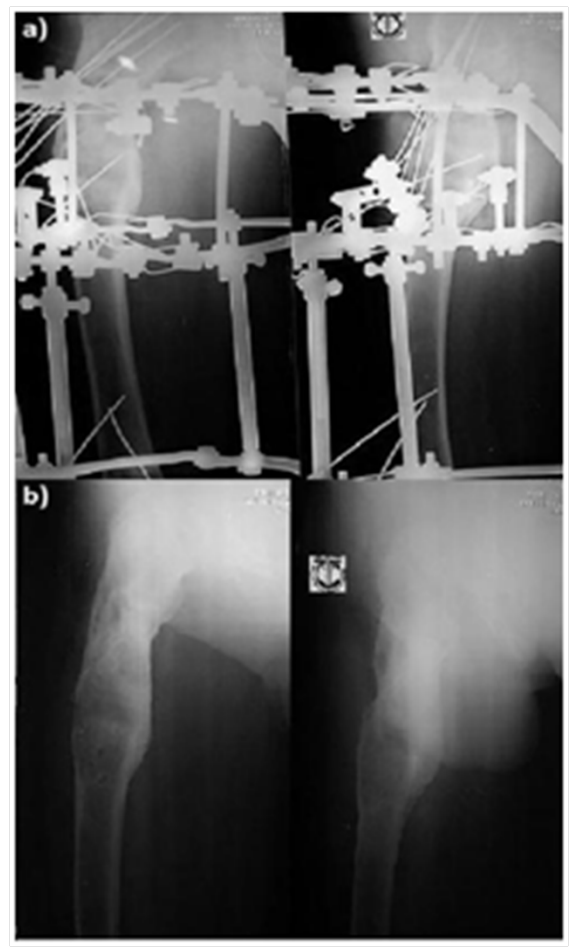

Figure 3 Radiograph showed thickening of the cortex around the fibrous dysplasia lesion and increased bone density. a. At 10 months on llizarov apparatus. b.After removal of llizarov apparatus.

\section{Discussion}

Lichtenstein first coined the term Fibrous dysplasia in 1938. He described it as a skeletal abnormality where the medullary cavities of involved bones filled with 'gritty, greyish white fibrous tissue containing trabeculae of newly formed primitive bone'. ${ }^{1}$ Fibrous dysplasia can occur as a solitary focus (monostotic form), in multiple bones (polyostotic), or polyostotic with association with other disorders. ${ }^{2}$ In 1937, Albright et al. ${ }^{3}$ described a syndrome characterised by polyostotic fibrous dysplasia that included: area of pigmentation, skeletal changes and endocrine failure; the most striking example is precocious puberty in girls. ${ }^{3}$

Fibrous dysplasia is caused by the sporadic mutation of the GNAS1 gene located on the chromosome of the osteoblastic cells. ${ }^{4}$ The abnormality of mutated osteoblast cells led to inapropriate differentition of mesenchymal cells resulting in imature bone cells. Fibrous dysplasia can occur in any bones. Lesions are found to occur in the ribs, proximal femur, tibia, humerus and craniofacial bones in decreasing order of incidence. Usually, fibrous dysplasia presents clinically in children and adolescents, with a median onset age of 8 years. Monostotic fibrous dysplasia is active while it is growing but often become inactive after puberty. Polyostotic disease typically remains active throughout life. Patients usually seek medical care because of either painful swelling and deformity or a pathological fracture through a weakend bone.

Monostotic fibrous dysplasia may be completely asymptomatic and is often an incidental finding on x-ray. Radio graphically, the characteristic appearance of fibrous dysplasia vary widely, it include a ground glass appearance, expansion of bone and sclerosis surrounding the lesion. ${ }^{5}$ Computerised tomography of fibrous dysplasia is useful in demonstrating the ground glass texture of the lesion and particularly helpful in defining the extend of bone involvement. ${ }^{6}$ Magnetic resonance imaging does not provide a characteristic appearance of fibrous dysplasia and therefore is a less useful imaging modality. ${ }^{7}$

Management of fibrous dysplasia depends on the intensity of the symptoms, site of the lesion, patient's age and the presence of a significant aesthetic deformity or fracture. ${ }^{8}$ Asymptomatic lesion found incidentally in patients with monostotic for generally requires no treatment. Bisphosphonate treatment of polyostotic and monostotic fibrous dysplasia have been reported to reduce pain and fracture rate of affected area; as well as reduction in size and filling in of bony defect in some cases. ${ }^{9}$

Various surgical interventions have been performed for the management of fibrous dysplasia. Traditionally, patient with fibrous dysplasia lesion over the proximal femur underwent intralesional currettage and filling with autogenous bone graft or allograft. However, unsatisfactory results such as bone graft resorption and recurrence of the lesion and progresion of varus deformity have been reported. ${ }^{10}$ Successful treatment by combinations of valgus osteotomy to correct shepherd's crook deformity and internal fixation with plate or intramedullary nailing have been reported. ${ }^{11,12}$ Ilizarov technique has been documented with good outcome in treating shepherd's crook deformity with pathological fracture. ${ }^{13}$ Sakurakichi et al. ${ }^{13}$ in treating 2 patients with Ilizarov apparatus argued that achieving mechanical alignment rather than resecting the bone lesion is more important, the well aligned limb will be less affected by shearing deforming forces as fibrous tissue matures after puberty.

The Ilizarov technique was also our method of choice in treating our patient. Shepherd's crook deformity involves large portion of the proximal femur resulting excessive varus deformation off the mechanical axis as well as limb shortening. A single procedure limits the correction angle attainable, so large deformity correction requires more than one procedure. ${ }^{14}$ Due to its versatility, the Ilizarov apparatus allows 3-dimensional correction of deformity, modification of the frame for residual deformity and simultaneously correction of limb length.

The Ilizarov technique provides stability and creates mechanical force to induce new bone formation. This can be accomplished by two separate biological processes: slow and steady traction on a living tissue creating stress that stimulates metabolic activation and osteogenesis by changing the mechanical environment at the pathological bone. ${ }^{15}$ The local blood supply and the integrity of the periosteum are well preserved by minimally invasive transosseos wires or when corticotomy is necessary. When vascularity is preserved at fracture site, the bone will unite within the normal healing period. ${ }^{16}$ And the greatest advantage after application of the Ilizarov apparatus is early weight bearing. Weight bearing is considered to be essential both for bone regeneration and consolidation.

\section{Conclusion}

The management of shepherd's crook deformity in fibrous dysplasia remains a challenge. The goal of treatment is to prevent further deformity, relieve pain and regain normal gait. We are of the same opinion as other authors that complete eradication of the lesion is not feasible and it is more important to achieve a good alignment of the bone. Restoring mechanical axis and improving bone quality of the pathological femur has been successfully achieved by the Ilizarov technique. 


\section{Acknowledgements}

This case was operated and managed in Bari-Ilizarov Orthopaedic Centre, Dhaka, Bangladesh.

\section{Conflicts of interest}

None.

\section{References}

1. Lichtenstein L. Polyostotic fibrous dysplasia. Arch Surg. 1928;36(5):874-898.

2. Lichtenstein L, Jaffe HL. Fibrous dysplasia of bone. A condition affecting one, several or many bones, the graver cases of which may present abnormal pigmentation of skin, premature sexual development, hyperthyroidism or still other extra skeletal abnormalities. Arch Pathol. 1942;33:777-816.

3. Albright F, Butler AM, Hampton AO, et al. Syndrome characterized by osteitis fibrosa disseminata, areas of pigmentation and endocrine dysfunction, with precocious puberty in females: report of five cases. New Eng J Med. 1937;216(17):727-746.

4. Di Caprio MR, Enneking WF. Fibrous dysplasia. Pathophysiology, evalustion, and treatment. J Bone Joint Surg Am . 2005;87(8):1848-1864.

5. Singer FR. Fibrous dysplasia of bone: The bone lesion unmasked. Am J Pathol. 1997;151(6):1151-1155.

6. Daffner RH, Kirks DR, Gehweiler JA, et al. Computed tomography of fibrous dysplasia. AJR Am J Roentgenol. 1982;139:943-948.

7. Norris MA, Kaplan PA, Pathria M, et al. Fibrous dysplasia: Magnetic resonance imaging appearance at 1.5 tesla. Clin Imaging. 1990;14:211-215
8. Enneking WF, Grearen PF. Fibrous dysplasia of the femoral neck. Treatment by cortical bone grafting. J Bone Joint Surg Am. 1986;68:1415-1422.

9. Chan B, Zacharin M. Pamidronate treatment of polyostotic fibrous dysplasia: Failure to prevent expansion of dyspllastic lesions during childhood. J Pediatr Endocrinol Matab. 2006;19:75-80.

10. Guille JT, Kumar SJ, MacEwen GD. Fibrous dysplasia of the proximal part of the femur. J Bone Joint Surg. 1998;80(5):648-658.

11. L Al-Mouazzen, K Rajakulendran, N Ahad. Fibrous Dysplasia, shepherd's crook deformity and an intra-capsular femoral neck fracture. Strat Traum Limb Recon. 2013;8:187-191.

12. Kataria H, Sharma N, Kanojia RK. One stage osteotomy and fixation using a proximal femoral nail and fibular graft to correct a severe shepherd's crook deformity in a patient with fibrous dysplasia: a case report. J Orthop Surg. 2009;17(2):245-247.

13. Sakurakichi K, Tsuchiya H, Yamashiro T, et.al. Ilizarov technique for correction of the shepherd's crook deformity: a report of two cases. $J$ Orthop Surg (Hong Kong). 2008;16(2):254-256.

14. Nagda TV, Singh H, Kandoi M, et al. Two stage reconstruction for the shepherd's crook deformity in a case of polyostotic fibrous dysplasia. $J$ Postgrad Med. 1997;43:83-84.

15. Bari MM. Correction of leg deformities and restoration of function of leg bones by Ilizarov technique. A color atlas of limb lengthening, surgical reconstruction and deformity correction by Ilizarov technique. 2016;pp.35-121.

16. Tsuchiya H, Tomita K, Matsumoto T, et al. Shepherd's crook deformity in fibrous dysplasia. Clin Orthop Relat Res. 1995;310:160-164. 